Portland State University

PDXScholar

1976

\title{
Medical and Nursing Students: Concepts of Self and Ideal Self, Typical and Ideal Work Partner
}

Ingrid Rein

Portland State University

Follow this and additional works at: https://pdxscholar.library.pdx.edu/open_access_etds

Part of the Nursing Commons, and the Psychiatry and Psychology Commons Let us know how access to this document benefits you.

Recommended Citation

Rein, Ingrid, "Medical and Nursing Students: Concepts of Self and Ideal Self, Typical and Ideal Work Partner" (1976). Dissertations and Theses. Paper 2382.

https://doi.org/10.15760/etd.2379

This Thesis is brought to you for free and open access. It has been accepted for inclusion in Dissertations and Theses by an authorized administrator of PDXScholar. Please contact us if we can make this document more accessible: pdxscholar@pdx.edu. 
AN ABSTRACT OF THE THESIS OF Ingrid Rein for the Master of Arts in Psychology presented November 17, 1976.

Tit7e: Medical and Nursing Students: Concepts of Self and Ideal Self, Typical and Ideal Work Partner

APPROVED BY MEMBERS OF THE THESIS COMMITTEE:
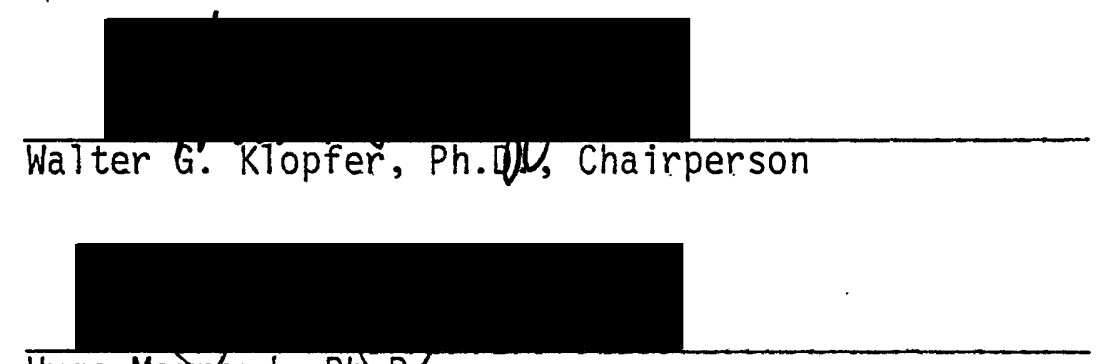

Hugo Maynárd, Ph.D.

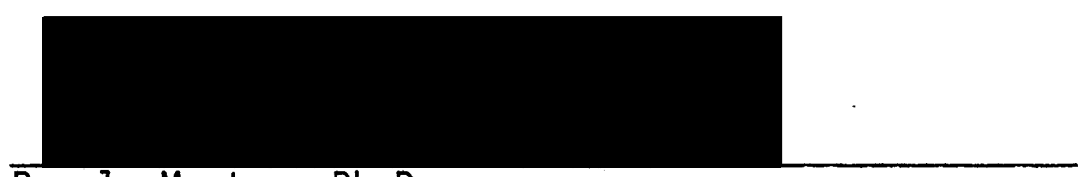

Pamela Munter, Ph.D.

A review was made of research concerning medical students, nursing students, physicians and nurses with special focus on the physician-nurse relationship. Research was carried out to investigate medical and nursing students' concepts of self, ideal self (as physician/nurse), typical work partner and ideal work partner.

Forty-three medical students and 78 nursing students participated in the study. Each subject filled out four copies of the ICL, each copy having a different set of instructions. The medical students were instructed to describe: 1) "you as you see yourself"; 2) "how you would ideally like to be as a physician"; 3) "what you consider to be the typical nurse"; and 4) "what you consider to be the ideal nurse." The nursing 
students were asked to describe: 1) "you as you see yourself"; 2) "how you would ideally like to be as a nurse"; 3) "what you consider to be the typical physician"; and 4) "what you consider to be the ideal physician."

The results show that both nursing and medical students have a significantly higher Dom score for ideal self than for self on the ICL. There is no significant difference in this respect in terms of Lov score for the nursing students, but the medical students have a significantly higher Lov score for ideal self than for self. As hypothesized, the nursing students' ideal self was found to have a significantly higher Dom score than the medical students' ideal nurse, but, contrary to expectation, the medical students' ideal self was found to have a significantly lower Dom score than the nursing students' ideal physician. In addition, tests were made to determine if sex and year in school had a significant influence on the subjects' responses. It was concluded that, generally, this was not the case. The few significant findings were discussed. It was established that there is a considerable discrepancy between typical and ideal nurse as described by medical students and between typical and ideal physician as described by nursing students. Finally, some significant differences were found when ideal self was compared with ideal work partner. It was concluded that both medical and nursing students want to change the traditional physician-nurse relationship. However, the data show lack of agreement as to what the new roles should be. It is suggested that increased communication between medical and nursing students with specific reference to future roles would result in a happier and more effective physician-nurse team. 
MEDICAL AND NURSING STUDENTS:

CONCEPTS OF SELF AND IDEAL SELF,

TYPICAL AND IDEAL WORK PARTNER

by

INGRID REIN

A thesis submitted in partial fulfillment of the requirements for the degree of

\author{
MASTER OF ARTS \\ in \\ PSYCHOLOGY
}

Portland State University

1976 
TO THE OFFICE. OF GRADUATE STUDIES AND RESEARCH:

The members of the Committee approve the thesis of Ingrid Rein presented November 17, 1976.
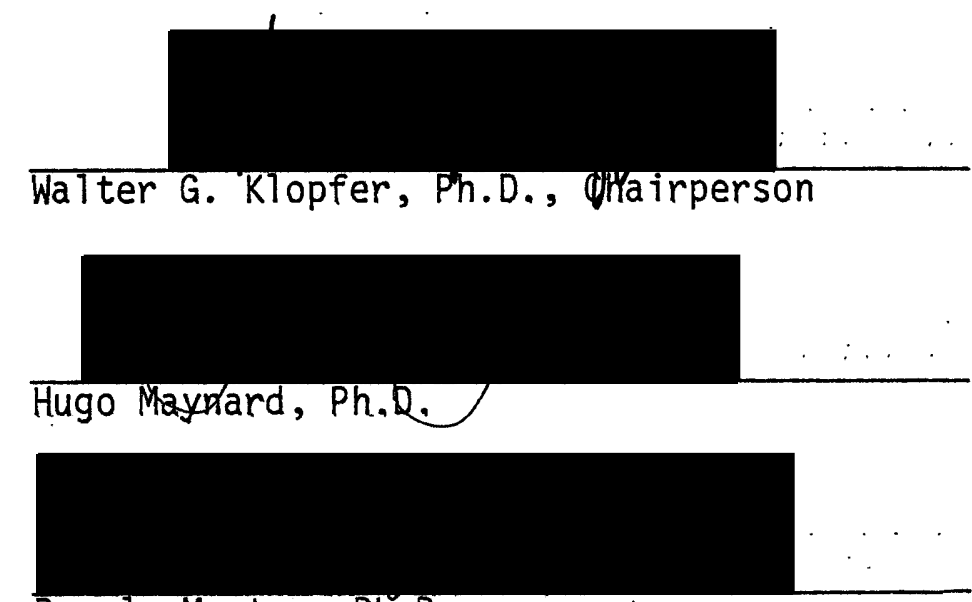

Pamela Munter, Ph.D.

\section{APPROVED :}
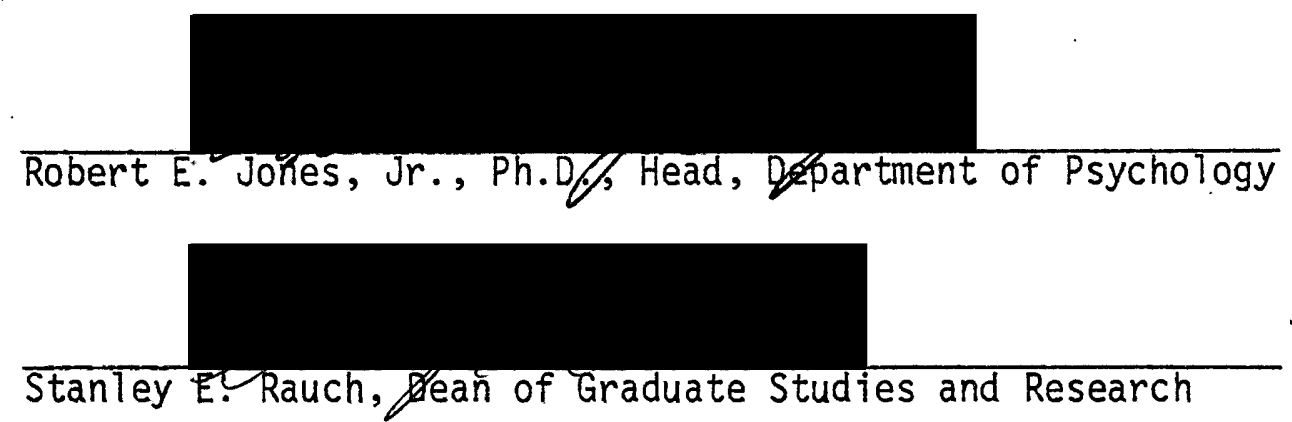

November 17,1976 
ACKNOWLEDGEMENTS

I wish to express my warmest appreciation to the many people who have given me help and support during the work on this thesis. In particular I wish to thank:

Doug Jeffrey for his invaluable help as a contact person with the University of Oregon Health Sciences Center School of Medicine; Pat McGuire for his persistent efforts with the computer; the members of my thesis committee for being both friendly and supportive; my husband, Daniel, for sharing the workload with me, and Thelma for her tireless typing. 
TABLE OF CONTENTS

PAGE

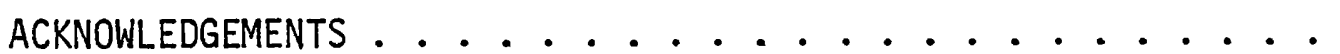

CHAPTER

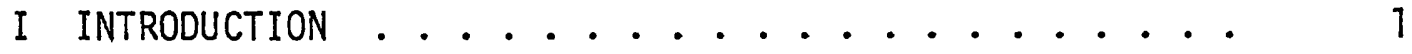

Nursing Students............. 3

Medical Students............. . . 4

Physician-Nurse Interaction ........ . 7

Hypotheses ............... . . 9

II METHOD ........................... 10

Subjects............... 10

Technique of Measurement and Design of Study ... 10

III RESULTS ........................ 13

IV DISCUSSION ..................... 20

BIBLIOGRAPHY ......................... 29

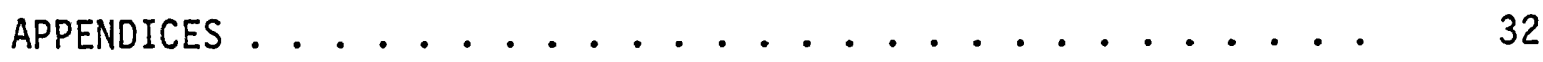

A. ICL Grid........................ 33

B. To the Participant.............. 34 


\section{LIST OF TABLES}

TABLE

PAGE

I Summary of Hypotheses ............. 13

II Summary of Data Used for Testing Hypotheses ................ 14

III Comparisons Based on Sex and Year in School ....... 16

IV The Typical vs. the Ideal Nurse and the

Typical vs. the Ideal Physician . . . . . . . . 18

$V \quad$ Ideal Self vs. Ideal Nurse Described by Medical

Students, and Ideal Self vs. Ideal

Physician Described by Nursing Students . . . . . . 19 


\section{INTRODUCTION}

Over the past few decades, the team approach has become firmly established in the field of health care. According to Kindig (1975), the team approach to health care delivery was first fully developed and recorded at New York's Montefiore Hospital in the late 1940's. A team consisting of a physician, a nurse and a social worker provided home-care services as a hospital outreach program. Around 1950 George Silver established the Family Health Maintenance Demonstration Project in conjunction with the Montefiore medical group. This project provided comprehensive family medical services, utilizing the team approach. George Silver became assistant secretary of HEW at the time the initial programs of the new Office of Economic Opportunity were being designed and funded. The influence of George Silver, which led to the mention of the team approach in the OEO Neighborhood Health Center Guidelines in 1966, may well have been critical to the popularization of the health team concept.

In addition to this official incentive, patient care has become increasingly complex over the years, and more and more people have become involved in the care of an $i 11$ person; a team approach is often the obviously most effective way of providing care. The nurse is ne. longer the subservient handmaiden whose only duty is to obey the physician's orders. The physician and the nurse form a team which at times may include various other health professionals. Leadership is at least theoretically distributed among the members of the team according to the task. As interdependence increases, so does the need for the physician and the nurse to work effectively together as a unit. 
Barbara Bates (1966) attempted to define the critical requirements of nurse-physician teamwork for good patient care. She collected 858 written reports of incidents of physician behavior (described by rurses) and 528 reports of incidents concerning nurse behavior (described by physicians). On the basis of an analysis of this written material, she concluded that it is of primary importance for good patient care that each member of the health team have some understanding of the view point of the other. Furthermore, she noted that good physician-nurse communication is not part of the usual medical school curriculum.

Benne and Bennis (1959) studied the nurse-physician relationship, as seen by nurses, by having a group of nurses complete cartoons involving nurse-physician interaction. Their results indicated that there was a considerable amount of conflict between the nurse and the physician, primarily due to the differing opinions physicians and nurses hold concerning the appropriate functions of the nurse.

Various explanations have been offered for the inadequate communication between the two health-team members. Some researchers have emphasized the physician's tendency to disclaim the need for others (Zaslove, Ungerleider and Fuller, 1968; Kane and Kane, 1969). The traditional pattern of male dominance-female submission has also been suggested as a key factor in physician-nurse friction (Stein, 1967). Rockoff (1973), using his own experiences as a medical student, explained that when a medical student first starts working in a hospital, he discovers that nurses and physicians make no attempt to understand each other's position. Interaction is based on a number of prejudices such as, "Nurses are reluctant to help physicians." The medical student quickly adopts the established manner of 
interaction with the nurse and he thereby helps perpetuate the pattern of no real physician-nurse communication. A similar explanation has been offered by Turk and Ingles (1963). They suggest that during the educational process, particularly during that part of it which takes place in a clinic or hospital, the medical and nursing students adopt the behavior norms shown by the professional group with which they identify (i.e., physicians and nurses). Turk and Ingles claim that the behavior pattern thus established is very difficult to change later.

Numerous researchers have investigated the personalities of nurses or nursing students and the personalities of physicians or medical students. However, only a few researchers have considered the two classes of health professionals from the point of view of a team.

\section{Nursing Students}

Some studies of nursing students have focused on the relationship between vocational choice and personality. The choice of nursing as a career has been viewed as a means of implementing a self-concept (Morrison, 1962). Pallone and Hosinski (1967) concluded that the occupational role is seen by nursing students as an opportunity to actualize an ideal self concept. The authors based their conclusion on the fact that they found close correspondence between concepts of ideal self and ideal nurse. Schoeberle and Craddick (1968) compared freshman and senior nursing students and found that the senior students rated themselves as being closer to the ideal nurse than did the freshmen. Davis and 0lesen (1965) conducted a study of the development of professional identities among student nurses. They found that the nurses held a quite orthodox view of the female role in American society. In keeping with this outlook 
on life the students consistently rated family as being of higher value to them than career. Davis and 0lesen studied the same students for three years and found no change of this point of view during this time span. The traditional view of the nurse as being submissive and fitting well into the feminine stereotype is supported by several studies (Bailey, Warshaw and Cohen, 1963; Ryback, 1968; Muhlenkamp and Parsons, 1972). Furthermore, withdrawal from nursing school has been associated with resentment of authority and with a greater need for independence (Kibrick, 1963; Muhlenkamp and Parsons, 1972). However, it should be noted that several of the studies are over ten years old. The last decade has seen considerable development within nursing in the direction of greater independence at work and increased insistence on the nurse being accepted as a health professional in her own right. In addition, the women's liberation movement has had a widespread influence, not only on student nurses but also on physicians, hospital administrators and so on. Consequently, one would not expect exactly the same findings today.

\section{Medical Students}

Several researchers who have, investigated the personality characteristics of medical school students have been concerned with personality changes over the four years spent in medical school. In 1955 Leonard Eron published a study which showed that during the period they spent in medical school medical students showed increased cynicism. A similar investigation of nursing students showed the opposite tendency (Eron, 1955b). The publication of these results led to a number of similar studies, and the "Eron assumption" became a term used to express the postulated relationship between medical school education and increased cynicism. In 1974 a review of the literature in this area was pubiished 
by Agnes G. Rezler. She concluded that medical schoot fosters cynicism through the structure of its curriculum and through its general atmosphere, and that courses designed to instill a more humanitarian attitude in the students have at best a temporary effect. In recent years, a study by Parlow and Rothman (1974) shows results similar to Eron's, whereas other studies cast doubt on the "Eron assumption" (Reinhardt and Gray, 1972; Perricone, 1974). Many changes have taken place since 1955 and medical students today are likely to be at least somewhat different from those who served as subjects for Eron's study. Maxmen (1971) describes a new breed of medical students who, according to him, despite the medical school environment, are vitally concerned with the quality of their interpersonal relations. He lists their core values as being humanitarianism, moral integrity and a desire for meaningful communication. If this description is at all characteristic of today's medical student, one would expect the change to be reflected both in the student's view of himself as a physician and in his view of the role of his work partner, the nurse.

McDonald (1962) studied personality characteristics of freshman medical students using the MMPI and the ICL (the Interpersonal Check List). Analysis of the ICL data showed that most of his subjects saw themselves mainly as managerial and competitive (octants 1 and 2) and that they would ideally like to be more critical and aggressive (octant 3). Another study (MCDonald and Gynther, 1963) compared medical students' ICL scores with those of other groups and with the medical student's academic performance. Comparing ICL self-description scores of medical students with similar scores from a group consisting of graduate students, clinical pastoral trainees and students in college extension courses, little difference was found. Both groups described themselves mainly as leaders and 
competitors. However, three times as many medical students described themselves as hostile. In terms of ICL self scores there were no significant differences between four groups of students, divided according to academic achievement. However, both those students with high aptitude scores and poor academic records and those with low aptitude scores but good academic records would ideally like to be more dominant than the students with low scores on the aptitude tests and poor academic performances. A third study using the ICL is relevant in this connection. Beard and Pishkin (1970) studied self-concept changes in fourth-year medical and nursing students and in a control group of psychiatric aides. ICL data on self and ideal self concepts were gathered before and after a 12-week period. The scores obtained were converted into the two summary scores, Dom and Lov. These two scores summarize the data in terms of the dominance/submission (Dom) and the love/hate (Lov) expressed by the subject on the check list. No significant difference on Lov scores was found in any comparison. However, there were a number of significant differences on the Dom measure. One significant difference was found when the self and ideal self scores were compared within each group. All groups revealed a significantly higher rating of Dom on ideal self than on self. In other words, all groups would ideally like to be more autocratic and dominant than they currently perceived themselves. The self-ideal self discrepancy as measured by Dom changed significantly over time for three of the five groups. For a group of nursing students taking a public health course the discrepancy decreased. Field work was an important part of this course, and Beard and Pishkin suggest that this experience boosted the students'. self esteem. For all the medical students 
the discrepancy increased due both to an increase in ideal self Dom and to a decrease in self Dom. This latter finding is attributed to the feeling on the part of the medical student that as graduation approaches he ought to be a self-confident leader, but he feels that his knowledge is inadequate for him to play this role.

Contrary to the Lov scores obtained by Beard and Pishkin, May Rawlinson (1964), using a group of nursing students, found Lov scores on ideal self to be significantly higher than Lov scores on self.

Physician-Nurse Interaction

A few studies have dealt directly with physician-nurse interactions. Of these studies, some have focused on the breakdown of communication between the physician and the nurse. This breakdown has been attributed partly to the organization of the clinic or the hospital, and partly to the structure of the educational institutions involved (Christman, 1965; Stein, 1967). While at school, nursing students and medical students have little to do with each other, so they form their ideas about medical and nursing care without communicating with their future work partner. When they start working in a hospital or a clinic and have an opportunity to relate to each other in a work situation, they quickly adopt the role models showed by nurses and physicians around them and, consequently, no real exchange of ideas takes place concerning their respective roles on the health team. (Lewis and Resnick, 1966). This lack of communication leads to differing opinions as to the amount of involvement nurses should have in making decisions (Davis, 1974).

Zaslove, Ungerleider and Fuller (1968) wondered how physicians' views of nurses' helpfulness to the patient would compare with nurses" 
views of the physicians' helpfulness to the patient. In their study, questionnaires were given to patients, nurses and physicians in a psychiatric hospital. Each group was asked to state what it considered to be the most helpful treatment modality involved (patients about themselves, nurses and physicians about those patients). The patients judged nursing care to be most important about 30 times as often as did the physicians, and the nurses judged physicians to be most helpful about 30 times as often as the reverse. In fact, the physicians saw the nurses as least helpful of all the treatment modalities. In a study by Scher, Ripley and Johnson (1975), third-year medical students were placed in a psychiatric ward and were expected to work with the psychiatric nurses. Some students intensely disliked this arrangement, and a general lack of communication between medical students and nurses was noticeable. The authors attributed this situation to the fact that the medical students learn nothing about nurses during their time in school. They expect subservience, but find independent nurses who consider themselves co-professionals and equal partners of the physician-nurse team. It should be mentioned, however, that psychiatric nursing is generally considered to have advanced faster and farther in the direction of equality and independence than other nursing specialties. A quite different result was found by Hofling, Brotzman, Dalrymple, Graves and Pierce (1966) in an experiment involving nurses from medical, surgical, pediatric and psychiatric wards. Twenty-two nurses received orders from a physician in an irregular manner to give an obviousty excessive dosage of a drug which was not authorized for use by the hospital. Twenty-one of the nurses obeyed the order without hesitation. A comparable group of nurses was 
asked by questionnaire what they would do in that situation. Ten out of tweive stated that they would not have obeyed the physician's order.

On the basis of the studies reviewed, it seems quite clear that in many instances physician-nurse communication leaves something to be desired. It has been suggested that the attitudes responsible for the lack of communication are shaped during the early years of medical and nursing school (Turk and Ingles, 1963; Lewis and Resnick, 1966). Consequentiy, any attempt to bridge the gap between nurses and physicians in the interest of a happier and a more efficient team should start early in the professional education of nurses and physicians,

\section{Hypotheses}

The study to be described in the following pages used medical and nursing students as subjects. The following hypotheses were examined:

1. Both nursing and medical students will have a significantly higher Dom score for ideal self than for self on the ICL. There will be no significant difference in this respect in terms of the Lov score.

2. Nursing students' ideal self will have a significantly higher Dom score than medical students' ideal nurse.

3. Medical students' ideal self will have a significantly higher Dom score than nursing students' ideal physician. 
CHAPTER II

METHOD

Subjects

The subjects for this study were 43 medical students and 78 nursing students enrolled at the University of Oregon Health Sciences Center Schools of Medicine and Nursing. Nine of the medical students were in their junior year (of these one was female and eight were male) and 34 were in their sophomore year ( 11 female and 23 male). In all, 12 female medical students and 31 male medical students participated in the study. The age of these subjects ranged from 22 to 36 years, the mean age being 24.79 and the mode being 24. (More than one-third of these subjects were 24 years old.) of the nursing students 32 were seniors (including two male students.) and 46 were juniors (there were no male students in this group). Because of the small number of male nursing students the scores for these two students were excluded from the statistical calculations. The age of the nursing students ranged from 20 to 46 , the mean being 23.10 and the mode 21. (Over one-half of the students were either 21 or 22 years 01d.)

Technique of Measurement and Design of Study

The instrument of measurement for this study was the ICL (Interpersonal Check List). The ICL is a 1ist of 134 adjectives and phrases describing interpersonal behavioral tendencies (e.g., "forceful", "apologetic," "eager to get along with others"). The subject is usually asked to describe his or her self-concept by checking off the adjectives and phrases that are appropriate for the description of the individual's self. However, other sets of instructions may be substituted, such as: 
"Describe your ideal self", or "Describe your mother", or, in this case, "Describe the ideal physician/nurse."

The ICL was developed by LaForge and Suczek (1955) in connection with Leary's interpersonal system of personality (Freedman, Leary, Ossorio and Coffey, 1957; Leary, 1957). A person's response on an ICL is of ten depicted on a circular grid which is divided into octants, each octant representing a different interpersonal style (see Appendix A). For research purposes the two summary scores Dom and Lov (Leary, 1956; LaForge, 1973) are often calculated. In this study the formulas used for calculations were those described by LaForge (1973). Dom reflects a person's score along the vertical Dominance/Submission axis, while Lov represents the person's score along the horizontal Love/Hate axis.

In this study each subject was asked to fill out four copies of the ICL, each copy having a different set of instructions. For the medical students the instructions were to describe: (1) "you as you see yourself"; (2) "how you would ideally like to be as a physician"; (3) "what you consider to be the typical nurse"; and (4) "what you consider to be the ideal nurse". The nursing students were asked to describe: (1) "you as you see yourself"; (2) "how you would ideally like to be as a nurse"; (3) "what you consider to be the typical physician"; and (4) "what you consider to be the ideal physician". The completion of the four questionnaires took $15-30$ minutes.

The questionnaires were administered to groups of students either at the beginning or at the end of a class period. Before the forms were handed out, the experimenter briefly explained the nature and the purpose of the project, how to fill out the forms, and how to be informed of the results of the study. Questions were encouraged and those who wished to 
participate were asked to fill out the questionnaires either immediately or at the end of the class period, depending on what arrangements had been made with the instructor. Those students who were unable to fill out the forms in the allotted time period or who preferred to fill out the forms later were encouraged to complete the questionnaires at their convenience, but as soon as possible, and were asked to mail them to the experimenter in a stamped, self-addressed envelope provided by the experimenter.

To each set of questionnaires was attached a brief explanation of the project, designed in accordance with University regulations (see Appendix B). All subjects were instructed to sign this page as evidence of their informed consent to participation in the project. To assure anonymity, the signed front page was removed immediately after the questionnaires had been filled out, and they were kept separately. Those who wished to return the questionnaires by mail were asked to sign the front page and to hand it to the experimenter before leaving the classroom. 
RESULTS

In Table I is a summary of the hypotheses for this study:

TABLE I

SUMMARY OF HYPOTHESES

Hypothesis

1. Both nursing and medical students will have a significantly higher Dom score for ideal self than for self on the ICL. .

There will be no significant difference in this respect in terms of the Lov score.

2. Nursing students' ideal self will have a significantly higher Dom score than medical students' ideal nurse.

3. Medical students' ideal self will have a significantly higher Dom score than nursing students' ideal physician.
Confirmed

Not Confirmed

$\star$

For Nursing

Students

For Medical

Students

The ICL asking the subjects to describe the typical nurse/physician was added after the above hypotheses for the study had been formulated. Therefore no hypothes is is attached to this ICL.

For a 11 comparisons both Dom and Lov scores were computed. Table II shows the data involved in the testing of hypotheses one, two and three. 
TABLE II

SUMMARY OF DATA USED FOR TESTING HYPOTHESES

Hypothes is 1 , medical students:

\begin{tabular}{|c|c|c|c|}
\hline $\begin{array}{l}x=\text { Dom values for ideal self } \\
y=\text { Dom values for self }\end{array}$ & $\begin{array}{l}N=43 \\
N=43\end{array}$ & $\begin{array}{l}\bar{x}=6.08 \\
\bar{y}=-0.93\end{array}$ & $t=6.94 * * \star$ \\
\hline $\begin{array}{l}x=\text { Lov values for ideal self } \\
y=\text { Lov values for self }\end{array}$ & $\begin{array}{l}N=43 \\
N=43\end{array}$ & $\begin{array}{l}\bar{x}=4.27 \\
\bar{y}=0.90\end{array}$ & $t=3.34^{* * *}$ \\
\hline
\end{tabular}

Hypothesis 1 , nursing students:

$\begin{array}{llll}x=\text { Dom values for ideal self } & N=76 & \bar{x}=7.15 & t=10.98^{\star * *} \\ y=\text { Dom values for self } & N=76 & \bar{y}=-1.35 & \\ & & & \\ x=\text { Lov values for ideal self } & N=76 & \bar{x}=5.67 & t=1.42 \\ y=\text { Lov values for self } & N=76 & \bar{y}=4.39 & \text { n.s. }\end{array}$

Hypothesis 2:

$\begin{array}{llll}x=\begin{array}{l}\text { Dom scores for nursing } \\ \text { students' ideal self }\end{array} & N=76 & \bar{x}=7.15 & t=4.03 * * * \\ y=\begin{array}{l}\text { Dom scores for medical } \\ \text { students' ideal nurse }\end{array} & N=43 & \bar{y}=4.83 & \\ x=\begin{array}{lll}\text { Lov scores for nursing } \\ \text { students' ideal self }\end{array} & N=76 & \bar{x}=5.67 & \begin{array}{l}t=-0.05 \\ \text { n.s. }\end{array} \\ y=\begin{array}{l}\text { Lov scores for medical } \\ \text { students 'ideal nurse }\end{array} & N=43 & \bar{y}=5.71 & \end{array}$

Hypothes is 3 :

$$
\begin{aligned}
x= & \text { Dom scores for medical } \\
& \text { students }{ }^{2} \text { ideal self } \\
y= & \text { Dom scores for nursing } \\
& \text { students }{ }^{\prime} \text { ideal physician }
\end{aligned}
$$$$
x=\text { Lov scores for medical }
$$$$
\text { students' ideal self }
$$$$
y=\text { Lov scores for nursing }
$$$$
\text { students' ideal physician }
$$

$N=43 \quad \bar{x}=6.08 \quad t=-2.40$

$N=76 \quad \bar{y}=7.29$

Note: This $t$-value is significant at .01 in the opposite direction. 
15

In addition to the comparisons involved in the three hypotheses, a number of others were made. For the medical students comparisons were made to determine whether the scores for female subjects differed significantly from those for male subjects. Since there were only two male nursing students among the subjects, a statistical analysis of difference in response based on sex was not meaningful for the nursing students and it was therefore omitted for this group. For both medical and nursing students comparisons were made to determine whether there were significant differences in response due to year in school. The results of these comparisons are shown below. (For these and the following comparisons a two-tailed t-test was used.) 
TABLE III

COMPARISONS BASED ON SEX AND YEAR IN SCHOOL

Medical students describing self:

$x=$ Dom scores for male students

$y=$ Dom scores for female students

$x=$ Lov scores for male students

$y=$ Lov scores for female students

$x=$ Dom scores for junior students

$y=$ Dom scores for sophomore students

$x=$ Lov scores for junior students

$y=$ Lov scores for sophomore students

Medical students describing ideal self:

$x=$ Dom scores for male students

$y=$ Dom scores for female students

$x=$ Lov scores for male students

$y=$ Lov scores for female students

$x=$ Dom scores for junior students

$y=$ Dom scores for sophomore students

$x=$ Lov scores for junior students

$y=$ Lov scores for sophomore students

$$
\begin{array}{lll}
N=31 & \bar{x}=-0.61 & t=0.56 \\
N=12 & \bar{y}=-1.77 & \text { n.s. } \\
N=31 & \bar{x}=-0.03 & t=-1.69 \\
N=12 & \bar{y}=3.13 & \text { n.s. } \\
N=9 & \bar{x}=1.07 & t=1.11 \\
N=34 & \bar{y}=-1.46 & \text { n.s. } \\
N=9 & \bar{x}=-0.43 & \text { t }=-0.81 \\
N=34 & \bar{y}=1.25 & \text { n.s. }
\end{array}
$$

$$
\begin{array}{lll}
N=31 & \bar{x}=5.83 & t=-1.01 \\
N=12 & \bar{y}=6.75 & \text { n.s. } \\
N=31 & \bar{x}=4.08 & t=-0.54 \\
N=12 & \bar{y}=4.76 & \text { n.s. } \\
N=9 & \bar{x}=6.76 & t=0.84 \\
N=34 & \bar{y}=5.91 & \text { n.s. } \\
N=9 & \bar{x}=3.66 & t=-0.56 \\
N=34 & \bar{y}=4.43 & \text { n.s. }
\end{array}
$$

Medical students describing the typical nurse:

$$
\begin{aligned}
& x=\text { Dom scores for male students } \\
& y=\text { Dom scores for female students } \\
& N=27 \quad \vec{x}=0.27 \\
& N=9 \quad \bar{y}=3.45 \\
& t=-1.40 \\
& \text { n.s. } \\
& x=\text { Lov scores for male students } \\
& y=\text { Lov scores for female students } \\
& N=27 \quad \bar{x}=0.94 \quad t=-2.32^{*} \\
& N=9 \quad \bar{y}=8.26 \\
& x=\text { Dom scores for junior students } \\
& y=\text { Dom scores for sophomore students } \\
& N=9 \quad \bar{x}=1.48 \quad t=0.24 \\
& N=27 \quad \bar{y}=0.92 \quad \text { n.s. } \\
& x=\text { Lov scores for junior students } \\
& y=\text { Lov scores for sophomore students } \\
& N=9 \quad \bar{x}=-3.37 \\
& N=27 \quad \bar{y}=4.81 \\
& t=-2.64 *
\end{aligned}
$$

(continued) 


\section{TABLE III}

COMPARISONS BASED ON SEX AND YEAR IN SCHOOL

(continued)

Medical students describing the ideal nurse:

$x=$ Dom scores for male students

$y=$ Dom scores for female students

$x=$ Lov scores for male students

$y=$ Lov scores for female students

$x=$ Dom scores for junior students

$y=$ Dom scores for sophomore students

$x=$ Lov scores for junior students

$y=$ Lov scores for sophomore students

$$
\begin{array}{lll}
N=31 & \bar{x}=4.50 & t=-1.13 \\
N=12 & \bar{y}=5.69 & \text { n.s. } \\
N=31 & \bar{x}=5.35 & t=-0.82 \\
N=12 & \bar{y}=6.66 & \text { n.s. } \\
N=9 & \bar{x}=5.85 & t=1.11 \\
N=34 & \bar{y}=4.56 & \text { n.s. } \\
N=9 & \bar{x}=3.55 & \text { t }=-1.58 \\
N=34 & \bar{y}=6.28 & \text { n.s. }
\end{array}
$$

Nursing students describing self:

$x=$ Dom scores for senior students

$y=$ Dom scores for junior students

$x=$ Lov scores for senior students

$y=$ Lov scores for junior students

$$
\begin{array}{lll}
N=30 & \bar{x}=-0.42 & t=1.08 \\
N=46 & \bar{y}=-1.96 & \text { n.s. } \\
N=30 & \bar{x}=5.26 & t=0.93 \\
N=46 & \bar{y}=3.83 & \text { n.s. }
\end{array}
$$

Nursing students describing ideal self:

$x=$ Dom scores for senior students

$y=$ Dom scores for junior students

$x=$ Lov scores for senior students

$y=$ Lov scores for junior students

$\begin{array}{lll}N=30 & \bar{X}=8.12 & t=2.34 * \\ N=46 & \bar{g}=6.53 & \\ N=30 & \bar{X}=4.95 & t=-1.19 \\ N=46 & \bar{y}=6.14 & \text { n.s. }\end{array}$

Nursing students describing the typical physician:
$x=$ Dom scores for senior students
$N=30$
$\bar{x}=12.92$
$t=1.03$
$y=$ Dom scores for junior students
$\bar{y}=11.95$
n.s.
$x=$ Lov scores for senior students
$N=30 \quad \bar{x}=-8.77$
$t=-0.31$
$y=$ Lov scores for junior students
$N=46 \quad \bar{y}=-8.40$
n.s.

Nursing students describing the ideal physician:
$x=$ Dom scores for senior students
$N=30$
$\bar{x}=8.21$
$t=2.56 *$
$y=$ Dom scores for junior students
$N=46$
$\bar{y}=-6.69$
$x=$ Lov scores for senior students
$y=$ Lov scores for junior students
$N=30 \quad \bar{X}=3.15$
$t=-1.74$
$N=46 \quad \bar{y}=4.46 \quad$ n.s. 
Comparisons were also made to determine whether there were significant differences between the typical and the ideal nurse as viewed by medical students and between the typical and the idear physician as viewed by nursing students. The results are presented below in Table IV.

TABLE IV

THE TYPICAL VS. THE IDEAL NURSE AND THE TYPICAL VS. THE IDEAL PHYSICIAN

$$
\begin{aligned}
& x=\text { Dom scores for the) } \\
& \text { typical nurse described } \\
& N=36 . \quad \bar{x}=1.06 \quad t=-3.58 * * * \\
& y=\text { Dom scores for the) by medical } N=43 \quad \bar{y}=4.83 \\
& \text { ideal nurse f students } \\
& x=\text { Lov scores for the) } \quad N=36 \quad \bar{x}=2.77 \quad t=-1.9 \text { ? } \\
& \text { typical nurse described } \\
& y=\begin{array}{l}
\text { Lov scores for the) } \\
\text { ideal nurse. }
\end{array} \quad \begin{array}{l}
\text { by medical } \\
\text { students }
\end{array} \quad N=43 \quad \bar{y}=5.71 \quad \text { n.s. } \\
& x=\text { Dom scores for the) } \\
& \text { typical physician) described } \\
& y=\text { Dom scores for the) by nursing } \quad N=76 \quad \bar{y}=7.29 \\
& \text { idear physician, students } \\
& x=\text { Lov scores for the) } \\
& \text { typical physician) described } \\
& y=\text { Lov scores for the) by nursing } \quad N=76 \quad \bar{y}=3.94 \\
& \text { ideal physician, students } \\
& N=76 \quad \bar{x}=12.33 \quad t=9.15 * * * \\
& N=76 \quad \bar{x}=-8.55 \quad t=-17.88 * * *
\end{aligned}
$$

$\star \star *$ = significant beyond .001 .

Finaliy, comparisons were made between medical students' concepts of ideal self and ideal nurse and between nursing students' concepts of ideal self and ideal physician. The results are presented in Table $V$. 
TABLE V

IDEAL SELF VS. IDEAL NURSE DESCRIBED BY MEDICAL STUDENTS, AND IDEAL SELF VS. IDEAL PHYSICIAN DESCRIBED BY NURSING STUDENTS

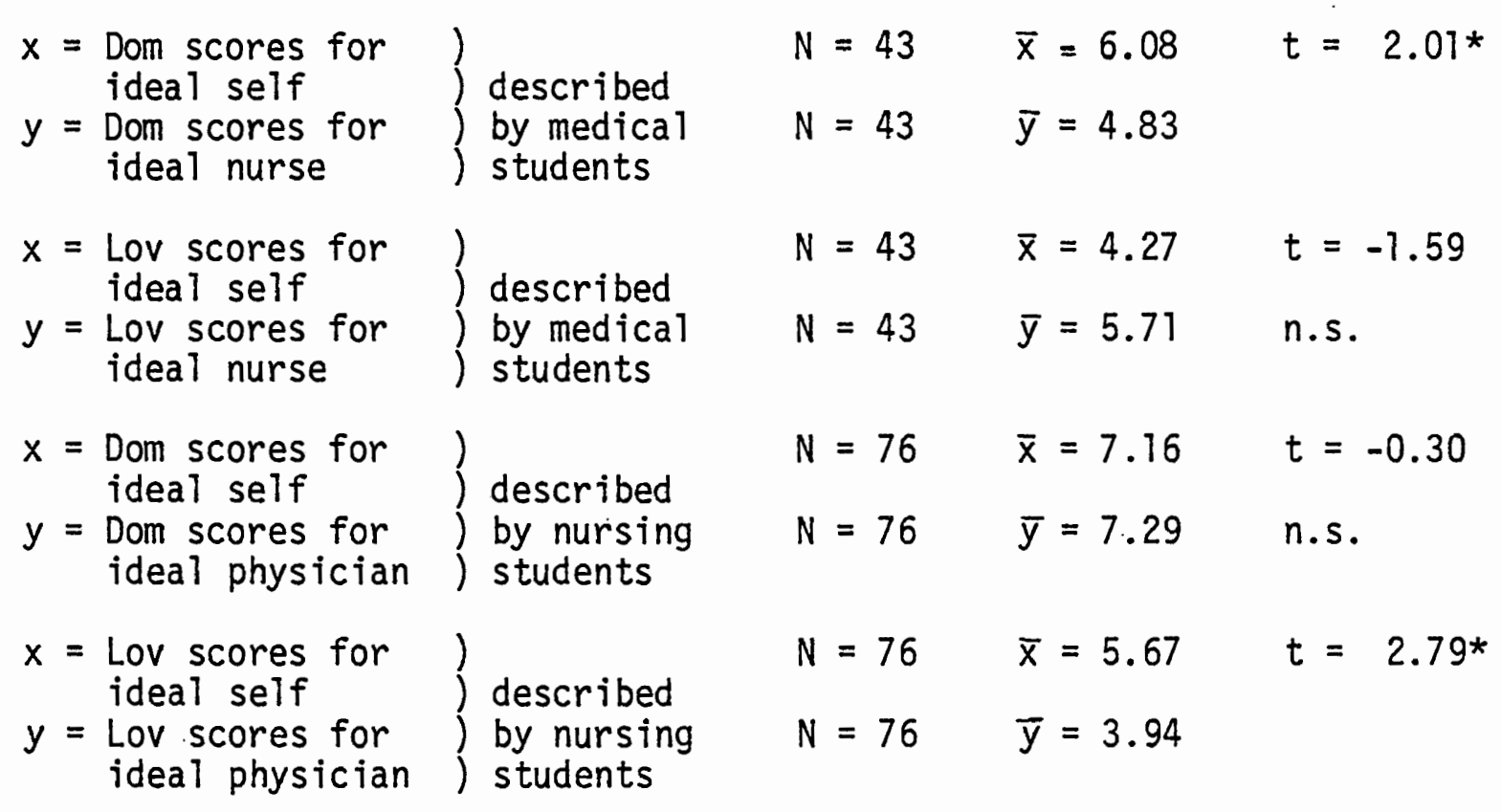

* = significant beyond .05 . 


\section{DISCUSSION}

The results of this study confirm the hypothes is that both medical and nursing students have a significantly higher Dom score for ideal self than for self on the ICL. This is in accordance with Beard and Pishkin's findings (1970). It is not a surprising result, and it is a conclusion one would expect to reach using other groups of subjects as well. Our culture rewards dominance, independence and other leadership qualities. Consequently, most people, not only medical and nursing students, would like to possess more of these characteristics. Beard and Pishkin found no significant differences in terms of Lov score, and they suggest that the question of how loving an individual should be is not a conflict area for medical and nursing students. May Rawlinson's results, on the other hand, suggest that nursing students would ideally like to be more loving than they currently perceive themselves (1964). The present study supports Beard and Pishkin's results by finding no significant self/ideal self discrepancy in terms of Lov scores for nursing students (thereby contradicting May Rawlinson's study). But, in disagreement with Beard and Pishkin's results, this study shows the difference to be significant for medical students.

It is understandable that medical students, trying to meet the rigorous requirements of medical school, might find that they are not as friendly and loving as they would ideally like to be as physicians. If one accepts the present results as being generally true for medical and nursing students, one explanation of the difference between the two groups may be that for the medical student to succeed in medical school he must 
devote most of his time and energy to meeting curriculum requirements, a context in which friendliness and love are not rewarded. In addition, the medical school program does not leave the student much free time in which to develop these personality characteristics. Nursing education, on the other hand, traditionaliy involves and rewards the ability to be loving and giving. In addition, nursing school may be less demanding on the student's time than medical school, thus allowing the nursing student the opportunity to satisfy needs outside of the student context.

The literature reviewed in Chapter I points to the area of authority as the main area of conflict for the physician-nurse team. The confirmation of hypothesis two (that nursing students' ideal self will have a significantly higher Dom score than medical students' ideal nurse) shows that while they are still students the stage is already being set for the nurse and the physician to be in disagreement when they begin to work together. This finding supports the suggestion by Turk and Ingles (1963) and Lewis and Resnick (1966) that the attitudes responsible for the lack of communication between nurse and physician are shaped before the nurse and physician enter the work force. This investigator agrees with the above-mentioned writers that it is during the time spent in medical and nursing school that something ought to be done to reach a consensus about future roles.

Hypothesis three, predicting that medical students' ideal self will have a significantly higher Dom score than nursing students' ideal physician was not confirmed. On the contrary, medical students' ideal seif had a significantly lower Dom score than nursing students' ideal physician. In other words, while the medical students would ideally like to be more 
dominant than they currently perceive themselves, they would not like to be as dominant as the nursing students would ideally like them to be. This particular outcome shows the medical students striving to get away from the traditional pattern of physician dominance and nurse submission and trying to establish a more equal relationship. As other results show, both medical and nursing students are to some extent moving away from the traditional extremes. They are not always in agreement, however, and this particular comparison shows the nursing students to be the greater supporters of the traditional pattern. Neither in this comparison nor in the data involved in hypothesis two were there significant differences in terms of Lov scores. In general, this study reflected more significant differences in terms of Dom scores than in terms of Lov scores, indicating that the area of authority and leadership is much more controversiai for the two health professionals than that of love and friendliness.

Table $V$ sheds some additional light on the extent to which medical and nursing students have been affected by the change in sex-determined patterns of behavior, commonly called the "women's lib movement". While the data involved in the rejection of hypothes is three showed the medical students' ideal self to have a significantly lower Dom score than the nursing students' ideal physician, Table $V$ shows the medical students' ideal self to have a significantly higher Dom score than the ideal nurse described by the medical students. Here we have an instance of the medical students emphasizing the physicians' authority over the nurse. In this comparison there was no significant difference in terms of Lov score. In the comparison by nursing students of ideal self with ideal physician no significant difference was found in terms of Dom score. 
In other words, while the nursing students would like the ideal physician to be more dominant than the medical students would ideally like to be as physicians, they would like to be equally dominant themselves. The notion of the nurse and the physician as equal partners of the health-team is emphasized here. In terms of Lov score, however, the nursing students" ideal self has a significantly higher value than the nursing students' ideal physician. Florence Nightingale ideals seem to be alive and well intermixed with strongly feminist notions.

One of the purposes of this study was to determine whether or not the sex of medical and nursing students influences the way in which they perceive themselves and their future work partner. Among the subjects in this study there were only two male nursing students; the scores for these two students were therefore excluded from the statistical calculations. However, their scores were in all cases within the range of those of the other subjects, and the two male subjects did not show a pattern of response that set them apart from the female nursing students.

of the eight comparisons made between the responses of male and female medical students, only one comparison showed a statistically significant difference. The Lov scores for male students describing the typical nurse were significantly lower than the Lov scores for female students in that description. While the difference in Dom scores for description of the typical nurse did not reach significance there was a clear tendency for the female medical students to give the typical nurse a higher Dom score than the male medical students did. This difference in the description of the typical nurse is presumably based on male and female medical students having had different experiences with nurses. 
This in turn is probabiy at least partiy due to the tendency of nurses (typically female) to respond differently to male and female medical students, and to the tendency of medical students to be influenced by traditional sex patterns in their interaction with nurses. The nurses may be both more dependent and less friendly when faced with a male medical student than when faced with a female medical student. In addition the male medical student may encounter the nurse with the expectation of a dominance/submission relationship, not looking for anything more and therefore not finding anything more in the relationship. The female medical student, on the other hand, may not share this expectation, but may be more interested in relating to the nurse as a person, and she may therefore experience nurses as being both more assertive and more friendly and sociable than does her male counterpart.

If the sex-determined difference in response-tendency in this particular comparison reflects a generally prevailing difference between male and female medical students, one would expect that an increase in the number of female physicians would be a significant factor in the breakdown of the traditional pattern of dominant physician-submissive nurse. However, in this study, only one out of eight comparisons showed a statistically significant difference based on sex. The results indicate agreement between female and male medical students as to concepts of self, ideal self and ideal nurse. Consequently, it will not necessarily be true that an increase in the number of women physicians wi11 be helpful in breaking down the traditional pattern of behavior between nurses and physicians and in establishing better communication between the two health team members. Change in this area may come as much or as little from male as from female medical students. 
This study was not designed specifically to measure the effect of year in school on attitudes. However, since both of the groups of subjects contained students from two different years in school, comparisons were made for nursing students as well as for medical students to determine if there were significant differences in scores depending on year in school. In the 16 comparisons made, only three statistically significant differences emerged. General1y, it must be concluded that attitudes do not seem to change significantly from one year to the next for nursing students and medical students. It should be noted, however, that the students in this study were from two consecutive years in school. Had freshman and senior students been compared, a greater number of significant differences might have been found. However, the purpose of this study was primarily to compare medical and nursing students, not to measure the effect on attitude of year in schoor.

For the medical students the only significant difference between sophomore and junior students was found in the description of the typical nurse. Junior students gave the typical nurse a considerabiy lower Lov score than did sophomore students. Obviously, the junior students have had more experience in working with nurses than the sophomore students. The difference between junior and sophomore students in this particular comparison may be because the junior students have come to know the typical nurse as being not as friendly as they once thought when their working experience was more limited. While the nursing students would like to be friendly and loving nurses, it appears that the roles which the system has set up for the two health professionals do not allow or encourage the nurse to develop and display these qualities in her interaction with the physician. A significant difference between junior and 
senior nursing students was found in the description of how the nursing students would ideally like to be as nurses. The senior students would ideally like to be more dominant than the junior students. This may be because the greater knowledge and experience of the senior students made them feel that as nurses they would like to be given more responsibility and independence than the junior students wished to have. Finally, year in school seemed to make a difference in the description of the ideal physician by nursing students where the Dom score for senior students was significantly higher than the Dom score for junior students. It may be that the senior students, through their increased work experience, have come to value more highly than the junior students the ability to make decisions and to take charge when necessary. This should not be thought of as an expression of wanting less independence for the nurse. Rather, as Table $V$ indicates, the nursing students consider independence and ability to lead as being desirable qualities for both the nurse and the physician.

The first half of Table IV compares the typical and the ideal nurse as described by the medical students. Of the 43 medical student subjects, seven did not complete the questionnaire describing the typical nurse, but instead wrote such comments on it as, "I never have had any contact with nurses," "Haven't had enough experience," and "Haven't worked with any nurses." The seven students who did not fill out this questionnaire were a11 at the end of their sophomore year. At that point in their education the medical students have accumulated a great deal of knowledge but, apparently, still do not know much about their future work partners.

It is clear from Table IV that both for medical and for nursing students there is a discrepancy between concepts of typical and ideal 
work partner. The data for the medical students show no significant difference in terms of Lov score between typical and ideal nurse, but the medical students describe the ideal nurse as being significantly more dominant than the typical nurse. This finding does not support the notion that the medical student wishes to preserve the traditional male dominance over "his" nurse. While he may interact with her on the assumption that she will show subservience, he may wish that she not do so. On the other hand, it should be remembered that medical students describe their ideal self as being significantly more dominant than the ideal nurse (Table V). So, while the medical students would like nurses to be more assertive and independent, they apparently do not want equality in this area. The nursing students have differing expectations (Table V), which may provide a source of conflict.

The data for nursing students in Table IV shows that the nursing students would like the ideal physician to be significantly less dominant and significantly more loving than they consider the typical physician to be. This seems to be a clear indication of dissatisfaction with the current physician-nurse relationship, and an expression of the nursing students' desire that the physician-nurse relationship be one both of greater equality and of greater human content.

The current study used medical and nursing students as subjects, and one might argue that the attitudes of medical and nursing students have little in common with the attitudes of physicians and nurses. It is the belief of this investigator that the attitudes of medical and nursing students do tell us something about current as well as future patterns of interaction between physician and nurse. The students' 
responses are based partly on actual experiences in a work situation and partly on ideais and expectations. The students are therefore both describing the current physician-nurse relationship as they see it, and also indicating the ways in which they are likely to attempt changes once they become physicians and nurses.

Clearly, the traditional pattern of interaction between physician and nurse is undergoing changes. The results of this study do not describe the simple stereotype of the (female) nurse wanting liberation from the (male) physician's authority and the (male) physician resenting this. Both medical and nursing students want change, but neither group wants too much change. Both groups are in effect saying, "Yes, we want change, but ..." However, as the results of this study indicate, the medical students and nursing students are certainly not in complete agreement either as to the areas of change or the amount of change they would like to see. Consequently, there is bound to be conflict between the two health-team members once they start working together. This state of affairs is not surprising, since there is virtually no communication between medical and nursing students while they are in school. However, it should not be impossible to remedy this deficiency and thereby improve communication and cooperation between physician and nurse in years to come. 


\section{Bibliography}

Bailey, Mattox A., L. Warshaw and J. Cohen. An obverse factor analytic study of values in psychologists, psychiatrists, social workers and nurses. Journal of Clinical Psychology, 19(1), 1963, 120-24.

Bates, Barbara. Nurse-physician teamwork. Medical Care, 4, 1966, 69-80.

Beard, Bruce H. and V. Pishkin. Self-concept changes in training medical and nursing students. Diseases of the Nervous System, 31., 1970, 616-23.

Benne, Kenneth $D$. and $W$. Bennis. The role of the professional nurse. The American Journal of Nursing, 59(2), 1959, 196-98.

Christman, Luther P. Nurse-physician communications in the hospital. Journal of the American Medical Association, 194(5), 1965, 539-44.

Davis, Margaret K. Intrarole conflict and job satisfaction on psychiatric units. Nursing Research, 23(6), 1974, 482-88.

Davis, Fred and V. L. 0lesen. The career outlook of professionally educated women. Psychiatry, 28(4), 1965, 334-45.

Eron, Leonard D. The effect of medical education on medical students' attitudes. Journal of Medical Education, 30, 1955, 559-566.

- The effect of nursing education on attitudes. Nursing Research, 4, 1955, 24-27.

Freedman, Mervin B., T. F. Leary, A. G. Ossorio, H. S. Coffey. The interpersonal dimension of personality. Journal of Personality, $20,1951,143-61$.

Hofling, Charles K., E. Brotzman, S. Dairymple, N. Graves and C. M. Pierce. An experimental study in nurse-physician relationships. Journal of Nervous and Mental Disease, 143(2), 1966, 171-80.

Kane, Robert L. and R. A. Kane. Physicians' attitudes of omnipotence in a university hospital. Journal of Medical Education, 44, 1969, 684-90.

Kibrick, Anne A. Drop-outs in schools of nursing: the effect of self and role perception. Nursing Research, 12, 1963, 140-49.

Kịndig, David A. Interdisciplinary education for priamary health care team delivery. Journal of Medical Education, 50(12 pt. 2)1975, 97-110.

La Forge, Rolfe, and R. F. Suczek. The interpersonal dimension of personality: III. An interpersonal checklist. Journal of Personality, 24, 1955, 94-112. 
La Forge, Rolfe. Using the ICL. Unpublsihed manuscript, 1973.

Leary, Timothy. Interpersonal Diagnosis of Personality. New York: The Ronald Press Company, 1957.

- Multilevel Meausurement of Interpersonal Behavior. Berkeley: Psychological Consultation Service, 1956.

Lewis, Charles E. and B. A. Resnick. Relative orientations of students of medicine and nursing to ambulatory patient care. Journal of Medical Education, 41, January-June 1966, 162-66.

Maxmen, Jerrold S. Medical student radicals: Conflict and resolution. American Journal of Psychiatry, 127(9), 1971, 1211-15.

McDonald, Robert L. Personality characteristics of freshman medical students as depicted by the Leary system. Journal of Genetic Psychology, $100,1962,313-23$.

McDonald, Robert L. and M. D. Gynther. Nonintellectual factors associated with performance in medical school. Journal of Genetic Psychology, 103, 1963, 185-94.

Morrison, Richard L. Self-concept implementation in occupational choices. Journal of Counseling Psychology, 9(3), 1962, 255-60.

Muhlenkamp, A. F. and J. L. Parsons. Characteristics of nurses: An overview of recent research published in a nursing research periodical. Journal of Vocational Behavior, 2, 1972, 261-73.

Pallone, Nathaniel J. and M. Hosinski. Reality testing a vocational choice: Congruence between self, ideal, and occupational percepts among student nurses. Personnel and Guidance Journal, 45, $1967,666-70$.

Parlow, J. and A. Rothman. Attitudes towards social issues in medicine of five health science faculties. Social Science and Medicine, $8(6), 1974,351-58$.

Perricone, Philip J. Social concern in medical students: A reconsideration of the Eron assumption. Journal of Medical Education, 49, $1974,541-46$.

Rawlinson, May E. A Study of Projection in Relation to Interpersonal Perception. Unpublished master's thes is, University of Portland, Portiand, 1964.

Reinhardt, Adina M. and R. M. Gray. A social psychological study of attitude changes in physicians. Journal of Medical Education, 47, 1972, 112-17. 
Rezler, Agnes G. Attitude changes during medical school: A review of the literature. Journal of Medical Education, 49(11), 1974, 1023-30.

Rockoff, Mark A. Interactions between medical students and nursing personnel. Journal of Medical Education, 48, July-December 1973, 725-31.

Ryback, David. The student nurse. Journal of Psychiatric Nursing and Mental Health Services, $6,1968,219-23$.

Scher, Maryonda E., H. S. Ripley and M. H. Johnson. Stereotyping and role conflicts between medical students and psychiatric nurses. Hospital and Community Psychiatry, 26(4), 1975, 219-21.

Schoeberle, Elizabeth A. and R. A. Craddick. Human figure drawings by freshman and senior student nurses. Perceptual and Motor Skills, $27,1968,11-14$.

Stein, Leonard I. The doctor-nurse game. Archives of General Psychiatry, 16, 1967, 699-703.

Turk, Herman and $T$. Ingles. Clinic Nursing: Explorations in Role Innovation. Philadelphia: F. A. Davis Co., 1963.

Zaslove, Marshall 0., J. T. Ungerleider and M. Fuller. The importance of the psychiatric nurse: Views of physicians, patients and nurses. American Journal of Psychiatry, $125(4), 1968,482-86$. 
APPENDICES 


\title{
APPENDIX A
}

\author{
INTERPERSONAL CHECK LIST
}

ILLUSTRATING THE CLASSIFICATION OF INTERPERSONAL BEHAVIORS INTO 16 VARIABLE CAIEGORIES

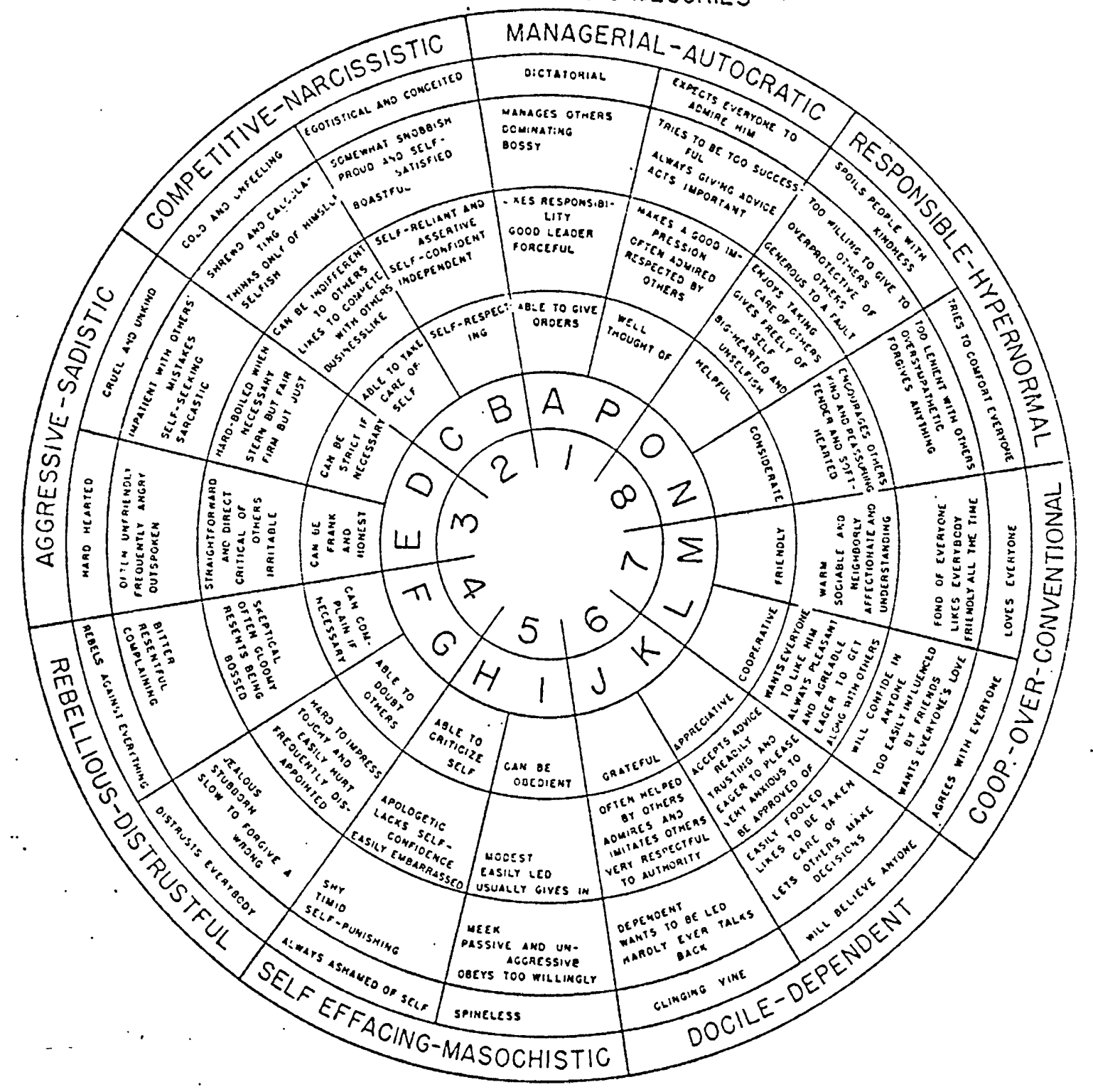


'To the participant:

This is a briwi toplanation of this rescarch project in which you have just been asked to participate: The project, which is entitled " $A$ study of Medical and Nur:ing students, Using the Interpersonal check Iist," is a project I an doing for my mastor's thesis at portland State University, where I am working with walter G. Klopfer, Ph. D. The project is an attempt to gather sone information in a systentatio way ubout how nectical and nursing students view themselves and how they would like to be as physicians and nurses. The project also asks nursing students to describe what they consider to be both the typical and the iaeal physician, and the medical students are asked to describe the typical and the ideal nurse.

This information about how medical and nursing students view thomselves and each other both actually and ideally should be of help in shcdang some light on physician-nurse interaction and communication patterns. Very little is known about this area, except that sometimes there are conflicts which affect the happiness of the physicians and nurses and the well-being of the patients.

It is understood that your participation is strictly voluntary, and that you may refuse to participate without any prejudice to your class standing. If you choose to participate, you will remain anonymous. Your signature is needed at the bottom of this page as evidence that you have read and understood this, but this page will be separated from the checklists as soon as you return them.

I would like to share with you the. information I obtain. From my point of view it is important that you get some feedback, and I will arrange to make that available to you in the form of a summary of my findings and conclusions. If you want me to mail this to you, please write your name and address on a separate piece of paper and hand it to me. If you have any questions, feel free to contact me either now or later.

Thank you very much for your cooperation.

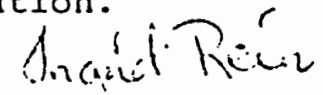
Ingrid Rein 3142 sw spring Garden st. Portland, oregon 97219 246-0621 